\title{
Perceived Barriers to Meditation Among College Students: The Role of Personality Traits
}

\author{
Samantha Whitford, MSW \\ Keith Warren, Ph.D. \\ The Ohio State University College of Social Work
}

\begin{abstract}
Background: Meditation is likely to be a useful intervention for anxiety and depression, and is increasingly common as a clinical intervention and informal practice among university students. However, meditation dropout rates are high, and it is likely that perceived barriers to meditation play a role. While neuroticism is known to predict dropout, there has been no study relating personality traits to these barriers.
\end{abstract}

Aim: To better understand the barriers to meditation practice that university students experience.

Methods: We used online survey data to analyze the relationship between personality traits, whether students practice meditation, time spent on academic and other work, and university students' perception of barriers to meditation.

Results: We found a nonlinear relationship between neuroticism and perceived barriers; the number of perceived barriers increased with increased neuroticism but eventually flattened out. Participants who meditate perceive more barriers than those who do not. We found no relationship between time spent in other activities and perception of barriers.

Conclusions: Those students who would benefit most from meditation may have the most trouble continuing. Clinicians applying meditation as an intervention in a university setting should be ready to work with students on barriers to practice.

Submitted 4 January 2019: accepted 28 February 2019

Keywords: meditation, barriers to meditation, neuroticism, mindfulness, university students

Meditation includes a wide variety of techniques for bringing attention to the breath, cognition, the body, a repeated word, or one's own stream of consciousness, with the goal of altering cognition and emotion (Dahl, Lutz, \& Davidson, 2015). Studies indicate that meditation can help reduce a person's depressive symptoms and relapse into depression (Cavanagh, Strauss, Forder, \& Jones, 2014; Eisendrath, Chartier, \& McLane, 2010; Peit , 2011; Kenny \& Williams, 2005; Klainin-Yobas, Cho, \& Creedy, 2011; Manicavasgar, Parker, \& Perich, 2010). Meditation is known to reduce stress and anxiety (Cavanagh et al., 2014; Sharma \& Rush 2014; Vollestad, Nielsen, \& Nielsen; 2011), and there is evidence that meditation improves hypochondria, which involves both stress and anxiety regarding health (Suraway, McMannus, Muse, \& Williams, 2014). Meditation is also known to help insomnia (Winbush, Gross, \& Kreitzer, 2007). There is also evidence that meditation may improve attention and memory (Sharma, 2015).

Anxiety and depression are the two most common mental health issues reported by college students (Center for Collegiate Mental Health, 2017) and so it is not surprising that meditation has seen increasing application with this 
population. In a meta-analysis of 25 studies of mindfulness meditation given to college students as treatment for anxiety, Bamber and Morpeth (2018) found a moderate to large effect size in most studies. There is exploratory evidence that mindfulness meditation improves the general sense of well-being of college students (Crowley \& Munk, 2016).

While meditation appears to benefit individuals with affective disorders, program compliance and retention are problematic. In a study of mindfulness-based self-help interventions, Cavanagh, Strauss, Forder, and Jones (2014) found that on average, across studies, $73 \%$ of participants completed meditation interventions, but that attrition rates could be as high as $52 \%$. In a meta-analysis of mindfulness based treatments of anxiety disorders, Vollestad, Nielsen, and Nielsen (2012) found attrition rates in individual studies as high as 45\%. In a study of loving-kindness meditation (LKM), Frederickson, Cohn et al. (2008) reported a rate of attrition due to noncompliance of $28 \%$. In a study of LKM as a treatment for back pain, Carson, et al. (2005) reported an attrition rate of $42 \%$. It is worth noting that nearly all intervention studies are short term, and that in the case of meditation, a skill that is intended to be practiced for years, any attrition figure is likely to be underestimated.

In an attempt to understand one possible source of program noncompliance, Berghoff, Wheeless, Ritzert, Wooley, and Forsyth (2017) assigned students to either ten minutes or twenty minutes of mindfulness meditation per day for two weeks. They found no statistically significant difference in compliance between the two groups. As they noted, however, programs such as Mindfulness Based Stress Reduction (MBSR) often involve considerably longer daily periods of practice, so it is possible that differences in compliance would appear if a third group were assigned to longer periods of meditation. Further, the time frame of the experiment was short-it is possible that differences in adherence would have appeared after a month or two.

Neuroticism is a personality trait that is known to be correlated with the presence of mood disorders such as anxiety and depression (Paulus, Vanwoerden, Norton, \& Sharp, 2016; Newby et al., 2017), for which meditation is frequently used as a clinical treatment (Cavanagh et al., 2014; Eisendrath et al., 2010; Peit, 2011; Kenny \& Williams, 2005; Klainin-Yobas et al., 2011; Manicavasgar e al., 2010). It has long been noted that neuroticism predicts compliance in studies of meditation. Delmonte (1980) found that neuroticism was negatively correlated with frequency of meditation practice. In a later, prospective study, Delmonte (1988) found that neuroticism predicted short-term compliance with a meditation schedule. More recently, Dobkin, Irving and Amar (2012) cite a number of studies suggesting that individuals with more volatile personalities may be at increased risk of attrition in studies of mindfulness based interventions, which typically occurs in the early stages. Thus, while there is evidence that long term practice of meditation can reduce neuroticism (Crescentini \& Capurso, 2015; Leung \& Singhal, 2004; Van Den Hurk et al., 2011), neuroticism appears to incline subjects toward lower levels of compliance in the early stages. In the absence of longitudinal studies, it is also possible that the common finding of lower levels of neuroticism in senior meditators partly represents a tendency of more neurotic meditators to drop out.

Why would someone who is high in neuroticism be less likely to comply with a meditation protocol, the long term effect of which would be to lower neuroticism? One possibility is that individuals who are higher in neuroticism perceive more barriers to meditation. Using a sample of 150 family caregivers of cancer patients, Williams, Van Ness, Dixon and McCorkle (2011) found that neuroticism was positively correlated with perceived barriers to meditation. No one has at this point replicated this finding with university students. Given the increased use of meditation in the clinical treatment of students, such a replication is justified. 


\section{METHODS}

This study was approved by a University Institutional Review Board prior to any data collection. All participants were currently enrolled in university level course work. A convenience sample of participants was recruited from a Midwestern university with a total enrollment of 59,482 through a series of emails sent from the university's Office of Student Life and College of Social Work. The emails were circulated to students at both graduate and undergraduate levels. Participants who consented to be part of the study were directed to a Qualtrics page where they could take the electronic survey. A five dollar Amazon gift card was given as an incentive for taking the survey.

Personality type was measured using the Big Five Inventory (BFI; John, Donahue \& Kentle, 1991). The BFI is a 44-item scale measuring extraversion, agreeableness, conscientiousness, neuroticism, and openness. Cronbach's alpha reliability of the BFI subscales ranges from $\alpha=.75$ to .90 , with a mean of over .80 and test-retest reliability over three months ranging from $r=.18-.90$. The BFI has also shown convergent validity with peer ratings of personality and other measures of Big Five personality traits (John \& Srivastava, 1999). Median test-retest reliability of the BFI has varied from $r=.66-.78$ in different studies of university students (Gnambs, 2016).

Participants' perceptions of barriers to meditation were measured using the 17-question Determinants of Meditation Practice Inventory (DMPI; Williams et al., 2011). The DMPI has a Cronbach's alpha of $\alpha=.87$ and a test-retest intraclass correlation coefficient of $r=.86(\mathrm{CI}=.82-.90)$. In addition to these two instruments, respondents were asked whether they meditated at all, if so the type of meditation they practiced, the highest degree they had completed, the number of hours they spent on work and school per week and their gender.

Analysis proceeded in two stages. In the first stage, a local regression curve was fit to a scatterplot of neuroticism as a predictor of barriers to meditation as a check for nonlinearity in the relationship. Local regression (LOESS) fits a weighted least squares regression function to a scatterplot within a moving window. It therefore allows the detection of nonlinear structure in scatterplots (Cleveland, 1979). For instance, if participants' perception of barriers to meditation rose rapidly at low levels of neuroticism but then flattened out, LOESS would produce a plot that showed this. The LOESS curve was fit using SAS Studio 3.5 (SAS Institute 2016), using a locally linear fit and a smoothing parameter of .6. Following this visual analysis, a Generalized Additive Model (GAM) was fit to the dataset. GAM allows regression using a scatterplot smoother, yielding a model using multiple predictors that is robust to departures from regression linearity assumptions (Hastie \& Tibshirani, 1986). The GAM was fit using the R package gam (Hastie, 2018). Alpha was set at .05, but probabilities are also reported.

\section{RESULTS}

Eighty-four percent of participants were female, while sixteen percent were male. Seventy percent of participants reported they had completed some college, with 15\% having an associate degree, 10\% a bachelor's degree, and 5\% a master's degree. A plurality of participants, 37\%, reported that they spent 11 - 20 hours per week completing school work and extracurricular activities, with 33\% reporting 21 - 30 hours, 12\% 31 - 40 hours, 10\% 40 hours or more, and 8\% 0 - 10 hours. Forty-three percent of respondents worked 0 - 10 hours at paid employment, 27\% worked 11 - 20 hours, 13\% worked 21 - 30 hours, 7\% worked 31 - 40 hours, and 10\% worked 40 or more hours. Sixty nine percent of respondents reported practicing meditation while 31\% reported not practicing. Of those who practiced meditation, $82 \%$ reported practicing mindfulness meditation, $12 \%$ concentration meditation, $33 \%$ physical meditation such as 
T'ai chi or yoga, and 16\% some other form of meditation. Thus, a considerable percentage of those who did meditate practiced more than one form of meditation.

In this administration, Cronbach's alpha was $\alpha=.830$ for the DMPI, $\alpha=.827$ for the BFI neuroticism subscale, $\alpha=.883$ for the BFI extraversion subscale, $\alpha=.726$ for the BFI agreeableness subscale, $\alpha=.787$ for the BFI conscientiousness subscale and $\alpha=.775$ for the BFI openness to experience subscale. Descriptive statistics for these variables can be found in Table 1 .

\section{Table 1}

\section{Descriptive Statistics for Determinants of Meditation Practice Inventory and Big Five Inventory Subscales}

\begin{tabular}{|c|c|c|c|c|}
\hline Variable & Minimum & Maximum & $\underline{\underline{\text { Mean }}}$ & $\underline{\underline{\text { Std. Deviation }}}$ \\
\hline Determinants of Meditation Practice Inventory & 16.00 & 64.00 & 39.1839 & 9.51196 \\
\hline Big Five Inventory Extraversion & 10.00 & 40.00 & 25.6471 & 7.31715 \\
\hline Big Five Inventory Agreeableness & 23.00 & 45.00 & 34.4048 & 5.19527 \\
\hline Big Five Inventory Conscientiousness & 15.00 & 43.00 & 31.1412 & 6.00823 \\
\hline Big Five Inventory Neuroticism & 13.00 & 39.00 & 26.6471 & 6.00735 \\
\hline Big Five Inventory Openness & 18.00 & 47.00 & 37.3095 & 5.95156 \\
\hline
\end{tabular}

Figure 1 shows the LOESS curve fit of the BFI neuroticism subscale as a predictor of perceived barriers to meditation as measured by the DMPI. The relationship is nonlinear. Estimated DMPI score shows a gradual exponential increase from 32 at a BFI neuroticism score of 16 to a peak of 45 at a BFI neuroticism score of 33, after which the relationship flattens out. 


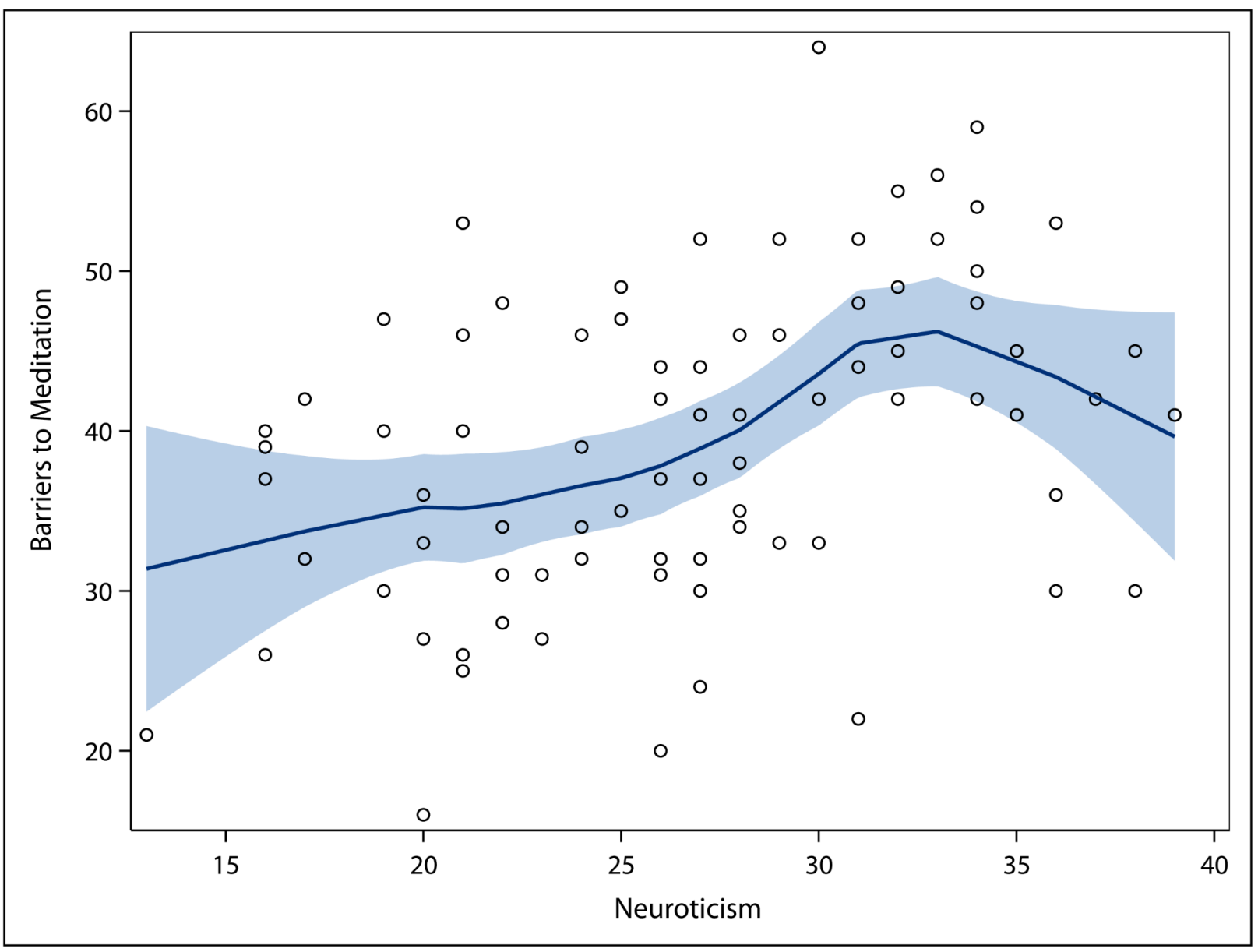

Figure 1. LOESS regression curve of neuroticism as a predictor of barriers to meditation, degree $=1$, smoothing parameter $=.6,95 \% \mathrm{CI}$.

\section{GAM MODEL}

Ninety-three participants began the survey. Six of those provided no data on either the DMPI or the BFI. Missing data on individual questions meant that an additional eight participants were excluded from the final GAM analysis due to listwise deletion of cases (Allison, 2001). The results of that analysis can be found in Table 2. 


\section{Table 2}

\section{Results of the Generalized Additive Model, Using the Determinants of Meditation Practice Inventory as the Dependent Variable}

$\begin{array}{llll}\text { Variable } & \text { Sum Sq. } & \underline{\text { F Value }} & \underline{\text { P Value }} \\ \text { Neuroticism } & 1333.4 & 20.7325 & >0.001 \\ \text { Extraversion } & 46.9 & 0.7289 & 0.39618 \\ \text { Agreeableness } & 29.9 & 0.4650 & 0.49759 \\ \text { Conscientiousness } & 16.0 & 0.2492 & 0.61920 \\ \text { Openness } & 22.7 & 0.3531 & 0.55432 \\ \text { Practice Meditation } & 1284.9 & 19.9782 & >0.001 \\ \text { Gender } & 148.7 & 2.3117 & 0.13298 \\ \text { Hours At School } & 245.8 & 3.8216 & 0.05465 \\ \text { Hours At Work } & 37.8 & 0.5870 & 0.44619\end{array}$

Among the Big Five personality traits, Neuroticism was a statistically significant predictor of DMPI (Sum Sq. = $1333.4, F$ value $=20.735, p$ value $<.001$ ), but this was not true of Extraversion, Agreeableness, Conscientiousness or Openness. Whether people practiced meditation was a statistically significant predictor of DMPI (Sum Sq. = 1284.9, $F$ value $=19.978, p$ value $<.001)$. Gender was not statistically significant, nor were hours spent at either school or work.

Following this initial model, nonsignificant variables were removed from the model sequentially in order to test for relationships that may have been suppressed due to collinearity. In particular, it seemed possible that hours spent at school might be a statistically significant predictor of DMPI if hours spent at work were removed from the model. But this was not the case. Elimination of hours spent at work led to no significant change in the parameter values associated with hours spent at school. Successive backward elimination of all variables other than neuroticism and the practice of meditation failed to yield any changes in statistical significance.

\section{DISCUSSION}

The analysis in this study found that both neuroticism and whether a student meditates predicted students' perception of barriers to meditation (Sum Sq. $=1333.4, F=20.735, p<.001$ and Sum Sq. $=1284.9, F=19.978, p<.001$, respectively). Neuroticism had a nonlinear relationship to that perception, first rising and then flattening out. No other personality traits were correlated with perceived barriers to meditation. However, the scores on conscientiousness and openness to experience were high, as might be expected for a sample of university students, and there may not have been enough variability in these variables to establish a relationship. Gender did not correlate with perceived barriers to meditation. Neither hours at school nor hours at work correlated with perceived barriers.

This study is clearly exploratory, consisting of a small convenience survey of university students. Since it is correlated with mood disorders, neuroticism is both an important variable itself, one of the Big Five personality traits (John \& Srivastava, 1999) and a valuable proxy measure for the presence of anxiety and depression. It seems likely that a personality trait such as neuroticism precedes an individual's perception of barriers to meditation, and it seems 
unlikely that perceived barriers to meditation would impel students to meditate. This reasoning suggests that the independent variables of statistical significance temporally precede the dependent variable.

The finding that neuroticism predicts perceived barriers to meditation offers an explanation for previous evidence that neuroticism predicts noncompliance with meditation (Delmonte, 1980; Delmonte, 1988; Dobkin et al., 2012). Since neuroticism has frequently been found to correlate with the presence of mood disorders (Paulus et al., 2016; Newby et al., 2017), the most common reason for referral to university counseling services (Center for Collegiate Mental Health, 2017), this raises an obvious difficulty with meditation as a treatment for these conditions. Those clients who need the intervention most are likely to perceive more barriers to doing it.

It may seem paradoxical that those students who practiced meditation would perceive more barriers to the practice, but commentary on this point goes back for at least 1,500 years. Both classic meditation manuals such as the Visuddhimagga (Buddhaghosa, 2003) and contemporary meditation manuals such as Mindfulness: A Practical Guide to Awakening (Goldstein, 2016) emphasize what Buddhist scriptures discuss as hindrances to meditation, such as restlessness or doubting the benefits of practice. A number of DMPI items, such as being unable to stop thoughts or not thinking that meditation can help one, directly echo these hindrances. In many cases, an individual is unlikely to notice these until he or she has begun practice, just as someone who does not exercise regularly is unlikely to understand the full difficulty involved.

University counselors who are using meditation as an intervention should be prepared to discuss barriers to meditation with their clients, and potentially to measure them with the DMPI. They should also monitor clients who are working on meditative interventions, both as part of the process of discussing barriers and to make sure that clients are actually meditating. While many meditative interventions are delivered in psychoeducational formats, it should be possible to take some time each week to discuss progress and barriers. Finally, alternative interventions such as cognitive behavioral therapy should be made available.

Researchers who are analyzing the relationship between neuroticism and barriers to meditation should be aware that linear models may underestimate the strength and statistical likelihood of this relationship. Moreover, studies of the relationship between neuroticism and barriers to meditation in clinical populations may fail to detect it, since the relationship is essentially flat at the high levels of neuroticism that are likely to characterize individuals in psychotherapy, particularly for mood disorders.

\section{CONCLUSION}

The use of meditation as a clinical intervention, particularly mindfulness meditation, has grown dramatically in the last two decades (Van Dam et al., 2018). Process research that looks at barriers to practice, reasons for attrition, teaching styles and possible negative effects, has grown more slowly. We hope that this article will encourage university counselors to look a bit more closely at the processes that students who practice meditation go through and the challenges they face. 


\section{REFERENCES}

Allison, P. D. (2001). Missing Data. Newbury Park, Ca: Sage Publications.

Bamber, M. D., \& Morpeth, E. (2018). The effects of mindfulness meditation on college student anxiety: A metaanalysis. Mindfulness. https://doi.org/10.1007/s12671-018-0965-5

Berghoff, C. R., Wheeless, L. E., Ritzert, T. R., Wooley, C. M. \& Forsyth, J. P. (2017). Mindfulness meditation adherence in a college sample: Comparison of a 10 -min versus 20 -min 2 week daily practice. Mindfulness, 8 , 1513-1521. https://doi.org/10.1007/s12671-017-0717-y

Buddhaghosa, B. (trans. Nanamoli; 2003). The Path of Purification: Visuddhimagga. Onalaska, Washington: Pariyatti Publishing.

Carson, J. W., Keefe, F. J., Lynch, T. R., Carson, K. M., Veeraindar, G., Fras, A. M., \& Thorp, S. R. (2005). LovingKindness Meditation for Chronic Low Back Pain. Journal of Holistic Nursing, 23(3), 287-304. https://doi.org/10.1177/0898010105277651

Cavanagh, K., Strauss, C., Forder, L., \& Jones, F. (2014). Can mindfulness and acceptance be learnt by self-help?: A systematic review and meta-analysis of mindfulness and acceptance-based self-help intervention. Clinical Psychology Review, 34, 118-129. https://doi.org/10.1016/j.cpr.2014.01.001

Center for Collegiate Mental Health (2017). Annual Report. Available at: https://sites.psu.edu/ccmh/files/2018/02/2017_CCMH_Report-1r4m88x.pdf

Cleveland, W. S. (1979), "Robust Locally Weighted Regression and Smoothing Scatterplots." Journal of the American Statistical Association, 74(368), 829-836. https://doi.org/10.1080/01621459.1979.10481038

Crescentini, C., \& Capurso, V. (2015). Mindfulness meditation and explicit and implicit indicators of personality and self-concept changes. Frontiers in Psychology, 6, 44. https://doi.org/10.3389/fpsyg.2015.00044

Crowley, C., \& Munk, D. (2016). An examination of the impact of a college level meditation course on college student well being. College Student Journal, 51(1), 91-98.

Dahl, C. J., Lutz, A., \& Davidson, R. J. (2015). Reconstructing and deconstructing the self: Cognitive mechanisms in meditation practice. Trends in Cognitive Sciences, 19(9), 515-523. https://doi.org/10.1016/j.tics.2015.07.001

DelMonte, M. M. (1980). Personality characteristics and regularity of meditation. Psychological Reports, 46, 703-712. https://doi.org/10.2466/pr0.1980.46.3.703

DelMonte, M. M. (1988). Personality correlates of meditation frequency and dropout in an outpatient population. Journal of Behavioral Medicine, 11(6), 593-597. https://doi.org/10.1007/bf00844908

Dobkin, P. L., Irving, J. A., \& Amar, S. (2012). For whom may participation in a mindfulness-based stress reduction program be contraindicated? Mindfulness, 3, 44-50. https://doi.org/10.1007/s12671-011-0079-9

Eisendrath, S., Chartier, M., \& McLane, M. (2011). Adapting Mindfulness-Based Cognitive Therapy for TreatmentResistant Depression. Cognitive and Behaviour Practice, 18:362-370.

https://doi.org/10.1016/j.cbpra.2010.05.004 
Frederickson, B. L., Cohn, M. A., Coffey, K. A., Pek, J. \& Finkel, S. M. (2008). Open hearts build lives: Positive emotions, induced through loving-kindness meditation, build consequential resources. Journal of Personality and Social Psychology, 95(5), 1045- 1062. https://doi.org/10.1037/a0013262

Gnambs, T. (2016). Sociodemographic effects on the test-retest reliability of the Big Five Inventory. European Journal of Psychological Assessment, 32(4), 307-311. https://doi.org/10.1027/1015-5759/a000259

Goldstein, J. (2016). Mindfulness: A practical guide to awakening. Louisville, Colorado: Sounds True.

Hastie, T. (2018). R package gam: Generalized Additive Models. Retreived from: https://cran.rproject.org/web/packages/gam/gam.pdf

Hastie, T., \& Tibshirani, R. (1986). Generalized Additive Models. Statistical Science, 1(3), 297-310. https://doi.org/10.1214/ss/1177013604

John, O. P., Donahue, E. M., \& Kentle, R. L. (1991). The Big Five Inventory--Versions 4a and 54. Berkeley, CA: University of California, Berkeley, Institute of Personality and Social Research. https://doi.org/10.1037/t07550-000

John, O. P., \& Srivastava, S. (1999). The Big Five trait taxonomy: History, measurement, and theoretical perspectives. In L. A. Pervin, \& O. P. John (Eds.), Handbook of Personality: Theory and Research (pp. 102-138). New York: Guilford Press.

Kenny, M.A., \& Williams, J.M.G. (2005). Treatment-resistant depressed patients show a good response to mindfulness-based cognitive therapy. Behaviour Research and Therapy, 45,617-625 https://doi.org/10.1016/j.brat.2006.04.008

Klainin-Yobas, P., Cho, M., \& Creedy, D. (2011). Efficacy of mindfulness-based interventions on depressive symptoms among people with mental disorders: A meta-analysis. International Journal of Nursing Studies, 49:109-121. https://doi.org/10.1016/j.ijnurstu.2011.08.014

Leung, Y., \& Singhal, A. (2004). An examination of the relationship between qigong meditation and personality. Social Behavior and Personality: An International Journal, 32(4), 313-320. https://doi.org/10.2224/sbp.2004.32.4.313

Manicavasgar, V., Parker, G., \& Perich, T. (2011). Mindfulness-based cognitive therapy vs. cognitive behavior therapy as a treatment for non-melancholic depression. Journal of Affective Disorders, 130:138-144. https://doi.org/10.1016/j.jad.2010.09.027

Newby, J., Pitura, V. A., Penney, A. M., Klein, R. G., Flett, G. L., \& Hewitt, P. L. (2017). Neuroticism and perfectionism as predictors of social anxiety. Personality and Individual Differences, 106, 263-267. https://doi.org/10.1016/j.paid.2016.10.057

Paulus, D. J., Vanwoerden, S., Norton, P. J., \& Sharp, C. (2016). From neuroticism to anxiety: Examining unique contributions of three transdiagnostic vulnerability factors. Personality and Individual Differences, 94, 38-43. https://doi.org/10.1016/j.paid.2016.01.012

Piet, J., Hougaard, E. (2011). The effect of mindfulness-based cognitive therapy for preventions of relapse in recurrent major depressive disorder: A systematic review and meta-analysis. Clinical Science Review, 31,10321040. https://doi.org/10.1016/j.cpr.2011.05.002 
SAS Institute Inc. 2016. SAS® Studio 3.5. Cary, NC: SAS Institute Inc.

Sharma, M., \& Rush, E. (2014). Mindfulness-based stress reduction as a stress management intervention for healthy individuals: A systematic review. Journal of Evidence-Based Complementary and Alternative Medicine, 19(4), 271-286. https://doi.org/10.1177\%2F2156587214543143

Sharma, H. (2015). Meditation: Process and effects. An International Quarterly Journal of Research in Ayurveda, 36(3), 233-237. https://doi.org/10.4103/0974-8520.182756

Surawy, C., McManus, F., Muse, K., Mark, J., \& Williams, G. (2015). Mindfulness-based cognitive therapy (MBCT) for health anxiety (Hypochondriasis): Rationale, implementation and case illustration. Mindfulness, 6:382-392. https://doi.org/10.1007/s12671-013-0271-1

Van Dam, N. T., Van Vugt, M. K., Vago, D. R., Shmalzl, L., Saron, C. D., Olendzki, A. ...Meyer, D. E. (2018). Mind the hype: A critical evaluation and prescriptive agenda for research on mindfulness and meditation. Perspectives on Psychological Science, 13(1), 36-31. https://doi.org/10.1177/1745691617709589

van den Hurk, P. A. M., Wingens, T., Giommi, F., Barendregt, H. P., Speckens, A. E. M., \& Van Schie, H. T. (2011). On the relationship between the practice of mindfulness meditation and personality: an exploratory analysis of the mediating role of mindfulness skills. Mindfulness, 2, 194-200. https://doi.org/10.1007/s12671-011-0060-7

Vollestad, J, Nielsen, M., \& Nielsen, G. (2012). Mindfulness- and acceptance - based interventions for anxiety disorders: A systematic review and meta-analysis. The British Journal of Clinical Psychology, 51, 239-260. https://doi.org/10.1111/j.2044-8260.2011.02024.x

Williams, A., Dixon, J., Van Ness, P., \& McCorkle, R. (2011). Determinants of meditation practice inventory: Development, content validation, and initial psychometric testing. Alternative Therapies in Health and Medicine, 17(5), 16-23.

Winbush, N., Gross, C., \& Kreitzer, M. (2007). The effects of mindfulness-based stress reduction on sleep disturbance: A systematic review. EXPLORE, 3(6), 585-59. https://doi.org/10.1016/j.explore.2007.08.003

Author correspondence may be addressed to:

Keith Warren, Ph.D.

The Ohio State University

College of Social Work

Stillman Hall, 213

1947 College Rd.

Columbus, OH 43210

warren.193@osu.edu 


\section{Acknowledgements}

The authors would like to acknowledge financial support from The Ohio State University College of Social Work and valuable consultation with Lauren Goodridge of the SAS Institute. 